Sección Médica / Medical

Artículo de investigación / Research paper

\title{
Transmisión vertical de virus dengue en Aedes spp. (Diptera: Culicidae) en Medellín, Colombia
}

\author{
Vertical transmission of dengue virus in Aedes spp. (Diptera: Culicidae) \\ in Medellín, Colombia
}

\author{
GUILLERMO L. RÚA-URIBE ${ }^{1}$; TATIANA M. GIRALDO-JARAMILLO²; \\ OMAR TRIANA-CHÁVEZ ${ }^{3}$; RAÚL ROJO ${ }^{4}$; ENRIQUE HENAO ${ }^{5}$; JULIANA PÉREZ-PÉREZ ${ }^{6}$
}

\begin{abstract}
${ }^{1}$ Ph. D. Grupo Entomología Médica (GEM), Facultad de Medicina, Universidad de Antioquia, Carrera 51D № 62-29, Laboratorio 321, Medellín, Colombia, guillermo.rua@udea.edu.co, https://orcid.org/0000-0002-9802-0194. ${ }^{2}$ M. Sc. Grupo Entomología Médica (GEM), Facultad de Medicina, Universidad de Antioquia, Carrera 51D No 62-29, Laboratorio 321, Medellín, Colombia, tmgirald@gmail.com, https://orcid.org/0000-0002-3318-8682. ${ }^{3}$ Ph. D. Grupo Biología y Control de Enfermedades Infecciosas (BCEI), Universidad de Antioquia, Calle 62 º 52-59, Laboratorio 620, Medellín, Colombia, omar.triana@ udea.edu.co, https://orcid.org/0000-0001-8031-0225. ${ }^{4}$ M. Sc. Secretaria de Salud, Alcaldía de Medellín. Plaza de la Libertad, Torre Administrativa, Piso 18, Calle 44 N 53A-11, Medellín, Colombia, raul.rojo@medellin.gov.co, https://orcid.org/0000-0002-4664-1351. ${ }^{5}$ Ingeniero Ambiental, Secretaria de Salud, Alcaldía de Medellín, Plaza de la Libertad, Torre Administrativa, Piso 18, Calle 44 № 53A-11, Medellín, Colombia, enrique.henao@medellin.gov.co, https:// orcid.org/0000-0003-4171-7262. ${ }^{6}$ M. Sc. Grupo Entomología Médica (GEM), Facultad de Medicina, Universidad de Antioquia, Carrera 51D N 62-29, Laboratorio 321, Medellín, Colombia,jperezp1017@gmail.com, https://orcid.org/0000-0002-5819-1917.
\end{abstract}

\begin{abstract}
Autor para correspondencia: Guillermo L. Rúa-Uribe, Ph. D. Grupo Entomología Médica (GEM), Facultad de Medicina, Universidad de Antioquia, Carrera 51D N ${ }^{\circ} 62-29$, Laboratorio 321, Medellín, Colombia, guillermo.rua@udea. edu.co, https://orcid.org/0000-0002-9802-0194.

Citación sugerida / Suggested citation: RÚA-URIBE, G. L.; GIRALDO-JARAMILLO, T. M.; TRIANA-CHÁVEZ, O.; ROJO, R.; HENAO, E.; PÉREZ-PÉREZ, J. 2020. Transmisión vertical de virus dengue en Aedes spp. (Diptera: Culicidae) en Medellín, Colombia. Revista Colombiana de Entomología 2020, 46 (1): e6973. https://doi.org/10.25100/ socolen.v46i1.6973
\end{abstract}

Recibido: 13-sep-2018

Aceptado: 21-ago-2019

Publicado: 27-ago-2020

Revista Colombiana de Entomología

ISSN (Impreso): 0120-0488

ISSN (En línea): 2665-4385

https://revistacolombianaentomologia.univalle.edu.co/

Open access

Publicadores / Publishers:

Sociedad Colombiana de Entomología SOCOLEN (Bogotá, D. C., Colombia) http://www.socolen.org.co Universidad del Valle (Cali, Colombia) http://www.univalle.edu.co/

(C) 2020 Sociedad Colombiana de Entomología - SOCOLEN y Universidad del Valle - Univalle
Resumen: El dengue es la arbovirosis más importante en salud pública. Es transmitido por la picadura de mosquitos hembras de Aedes spp., que se infectan de manera horizontal al ingerir sangre de una persona virémica. Sin embargo, numerosos estudios han identificado la transmisión vertical como otro mecanismo de infección vectorial. Con el propósito de analizar la ocurrencia de transmisión vertical del virus dengue por mosquitos Aedes, se recolectaron mosquitos adultos en viviendas y otras locaciones durante los levantamientos de índices entomológicos realizados por la Secretaría de Salud de Medellín en los años 2016 (epidémico) y 2017 (endémico). Los ejemplares se identificaron y conformaron pools para la detección viral por RT-PCR. En total se recolectaron 6.708 mosquitos, donde, el $96 \%$ y $4 \%$ correspondieron a Ae. aegypti y Ae. albopictus, respectivamente. De los 2.211 pools conformados, 294 resultaron positivos para virus dengue, y 50 de estos correspondieron exclusivamente a machos de Aedes spp. Tanto para el año epidémico como endémico, se registró transmisión vertical, pero fue más frecuente en el 2016. Se observó transmisión vertical en todos los sectores de la ciudad, sin un patrón definido. La presencia de machos Aedes spp. infectados naturalmente con virus dengue sugiere que la transmisión vertical es un evento más frecuente de lo que se consideraba, y podría comprender una mayor relevancia epidemiológica. Estudios adicionales para verificar la capacidad de infección del virus detectado en mosquitos machos y precisar el papel de la transmisión vertical en la incidencia de dengue se hacen necesarios.

Palabras clave: Salud pública, Aedes aegypti, infección natural, transmisión transovarial, vigilancia virológica.

Abstract: Dengue is the world's most important arbovirus. It is transmitted by the bite of females Aedes spp. mosquitoes, which normally become infected by biting a viraemic host. There are, however, numerous studies that have identified vertical transmission as a rare yet important mechanism of vector infection. This study was conducted in order to quantify the occurrence of vertical transmission of dengue virus in Aedes mosquitoes collected by the Secretary of Health in Medellin, Colombia in 2016 (epidemic year) and 2017 (endemic year). Specimens were identified to species and tested for dengue in pools by RT-PCR. A total of 6,708 mosquitoes were collected; $96 \%$ were Ae. aegypti, and $4 \%$ were Ae. Albopictus. 294 of 2,211 pools tested were positive for dengue virus, and 50 of the positive pools were exclusively male mosquitoes. For both epidemic and the endemic years, vertical transmission was detected, though it was more frequent in 2016. Vertical transmission was observed in mosquitoes collected from all sectors of the city, without a distinct spatial pattern. Our results suggest that vertical transmission is a more frequent event with greater epidemiological relevance than previously estimated. Additional studies are required to verify the infectivity of the virus detected in male mosquitoes and to specify the role of vertical transmission in the incidence of dengue virus.

Keywords: Public health, Aedes aegypti, natural infection, transovarial transmission, virological surveillance. 


\section{Introducción}

El dengue es la enfermedad viral transmitida por vectores de mayor relevancia a nivel global (World Health Organization 2014). La mitad de la población en el mundo se encuentran en riesgo de infección (Bhatt et al. 2013) y, en las últimas décadas, se registra una tendencia creciente en el número de casos y de países afectados, así como epidemias con mayor frecuencia y magnitud (Gubler 1989; World Health Organization y Special Programme for Research and Training in Tropical Diseases 2009; Dubot-Pérès 2013; Roth et al. 2014).

Esta enfermedad es causada por el virus dengue (DENV), del cual se reconocen tradicionalmente cuatro serotipos (Velandia y Castellanos 2011). Recientemente, en Malasia fue descubierto un quinto serotipo, pero de distribución principalmente local y selvática (Mustafa et al. 2015). El virus es transmitido horizontalmente, es decir de persona a persona mediante la picadura de mosquitos hembra del género Aedes (Diptera: Culicidae), principalmente Ae. (Stegomyia) aegypti (Linnaeus, 1762) y Ae. (S.) albopictus (Skuse, 1894) (World Health Organization 2014). Sin embargo, diferentes estudios en condiciones naturales y experimentales, han demostrado que el virus también puede ser transmitido verticalmente, es decir, de un mosquito hembra a su progenie, mediante infección transovarial o durante la ovoposición (Rosen 1987; Thenmozhi y Hiriyan 2007; Lequime et al. 2016).

En Colombia, el dengue representa un grave problema en salud pública debido a la intensa transmisión, la circulación simultánea de los cuatro serotipos y la presencia de los vectores en más del $90 \%$ del territorio nacional situado por debajo de los $2.200 \mathrm{msnm}$ (Padilla et al. 2012), aunque recientemente se reportó en altitudes superiores (Ruiz-López et al. 2016). Cali, Medellín, Cúcuta y Bucaramanga, entre otras ciudades, han sido clasificadas como hiperendémicas por la gran cantidad de casos que notifican cada año (Instituto Nacional de Salud 2016).

En Medellín, el dengue se registra en todos los barrios de la ciudad y presenta un comportamiento endemo-epidémico, con años de hiper epidemia(Sistema Nacional de Vigilancia en Salud Pública - Instituto Nacional de Salud 2018a). Particularmente en 2016, en la ciudad se notificó la mayor epidemia de dengue de la cual se haya tenido registro, con más de 19 mil casos, lo cual correspondió a un incremento de más del $400 \%$ con relación al año anterior, que también fue epidémico (Sistema Nacional de Vigilancia en Salud Pública Instituto Nacional de Salud 2018a). Sin embargo, esta situación no fue exclusiva de Medellín, e incluso, en otras ciudades del país la problemática fue mayor (Instituto Nacional de Salud 2016). Para 2017, en la ciudad se registró una disminución significativa en el número de casos (2.322), clasificándose dicho año como endémico (Sistema Nacional de Vigilancia en Salud Pública - Instituto Nacional de Salud 2018a).

Para priorizar las áreas de intervención para el control de dengue en Medellín, las autoridades de salud han implementado una estrategia de monitoreo vectorial $\mathrm{y}$ vigilancia entomo-virológica. El monitoreo se realiza empleando ovitrampas distribuidas uniformemente en toda la ciudad (polígonos de Thiessen), y revisadas semanalmente para cuantificar el número de huevos y el riesgo entomológico por trampa, barrio y comuna. La vigilancia virológica se realiza recolectando mosquitos en las viviendas cercanas a las ovitrampas, los cuales, son procesados por técnicas moleculares para la detección viral (Chow et al. 1998; Kow et al. 2001; Pérez-Pérez et al. 2017). Estas estrategias han permitido monitorear también la distribución espacial de $A e$. albopictus, vector primario de dengue para algunos países del sureste asiático (Gratz 2004) y Europa (Gjenero-Margan et al. 2011; Medlock et al. 2015) y que, en Medellín, podría estar contribuyendo a la transmisión de dengue, debido a que se ha encontrado naturalmente infectado con el virus (Pérez-Pérez et al. 2018).

Con la estrategia de vigilancia entomo-virológica en Medellín ha sido posible monitorear la distribución espacio/ temporal de los mosquitos naturalmente infectados con virus dengue y determinar la circulación de los serotipos predominantes. En el presente estudio se analiza la infección natural de mosquitos machos Ae. aegypti y Ae. albopictus, como indicador de transmisión vertical de virus dengue en la ciudad y se discute acerca de las implicaciones epidemiológicas que pueden representar estos hallazgos en la transmisión del virus. Estos resultados proveen información relevante para mejorar la comprensión de la compleja dinámica de transmisión de dengue.

\section{Materiales y métodos}

Área de estudio. El estudio se realizó en Medellín, Colombia (75'34'05'O 6 $\left.6^{\circ} 13^{\prime} 55^{\prime \prime} \mathrm{N}\right)$, ubicada a $1.450 \mathrm{msnm}$; con una extensión de $376,2 \mathrm{~km}^{2}$. La ciudad es atravesada, de sur a norte, por el río Medellín, que la divide en dos grandes subsectores: oriental y occidental. La latitud y altitud de la ciudad dan como resultado un clima subtropical sub húmedo, con una temperatura ambiental que oscila entre 16 y $28^{\circ} \mathrm{C}$ y una precipitación media anual de $1.656 \mathrm{~mm}$, y aunque no presenta estaciones al comienzo y mitad del año son frecuentes los periodos secos, y el resto del año el clima es variable (Alcaldía de Medellín 2003). Las condiciones climáticas generan un entorno ecoepidemiológico apto para la transmisión autóctona de dengue, Zika y chikungunya (Instituto Nacional de Salud 2016; Sistema Nacional de Vigilancia en Salud Pública - Instituto Nacional de Salud 2018b).

Recolecta de mosquitos. Los ejemplares se recolectaron en los años 2016 y 2017 durante los levantamientos de índices aédicos que se realizan trimestralmente (marzo, junio, septiembre y diciembre) por la Secretaría de Salud de Medellín (SSM). Para determinar las viviendas a muestrear se empleó el sistema de monitoreo vectorial de la SSM, conformado por 250 ovitrampas ubicadas uniformemente en toda la ciudad. Se visitaron a conveniencia entre cuatro y 18 viviendas cercanas a cada una de las trampas. También se recolectaron mosquitos provenientes de instituciones de salud y educativas. En todos los casos, los ejemplares se recolectaron con jama o aspirador entomológico mediante búsqueda activa. Los mosquitos recolectados se almacenaron en tubos Falcon ${ }^{\circledR}$ de $50 \mathrm{ml}$, con tapa de tela tipo tul, y transportados vivos hasta el laboratorio de Entomología Médica de la Universidad de Antioquia, para su identificación taxonómica siguiendo la clave morfológica de Rueda (2004). Posteriormente, se conformaron pools por especie (Ae. aegypti y Ae. albopictus), ubicación de ovitrampa y sexo. Los pools se conformaron desde uno hasta diez mosquitos. En algunas ocasiones se conformaron pools con ejemplares de ambos sexos para optimizar recursos en las pruebas moleculares. Los ejemplares se llevaron 
al laboratorio de Biología y Control de Enfermedades Infecciosas (BCEI) de la Universidad de Antioquia para el análisis y detección molecular del virus dengue.

Análisis molecular. Para la detección viral se empleó la técnica de reacción en cadena de la polimerasa con transcriptasa reversa (RT-PCR). Para ello, cada pool se maceró mecánicamente, siguiendo el protocolo recomendado por el fabricante. La extracción del ARN se realizó utilizando el kit comercial de RNeasy Mini Kit (Qiagen), y la síntesis del ADN copia (ADNc) se hizo utilizando $10 \mu \mathrm{L}$ del ARN extraído, $1 \mathrm{X}$ de tampón específico de la transcriptasa reversa, $1 \mathrm{mM}$ de dNTPs, $10 \mu \mathrm{M}$ de un cebador directo específico del virus dengue (DV1-5'-GGRACKTCAGGWTCTCC-3') y $1 \mu \mathrm{L}$ de transcriptasa reversa (Fermentas) con incubación a $42{ }^{\circ} \mathrm{C}$ por una hora e inactivación de la enzima a 94 ${ }^{\circ} \mathrm{C}$ por 10 minutos. Para la amplificación del virus se utilizaron $3 \mu \mathrm{L}$ del ADNc, 1X de tampón, 2,0 mM de $\mathrm{MgCl}_{2}, 0,2 \mathrm{mM}$ de dNTPs, 0,2 $\mu \mathrm{M}$ de cada uno de los cebadores específicos inversos para los cuatro serotipos del virus (DV1-5'-AGTTTCTTTTCCTAAACACCTCG-3', DV2-5'-CCGGTGTGCTCRGCYCTGAT-3', DV3-5' TTAGAGTYCTTAAGCGTCTCTTG-3' y DV4-5'CCTGGTTGATGACAAAAGTCTTG-3) y 0,5 U de taq polimerasa.

La amplificación por PCR se realizó a una temperatura inicial de $95^{\circ} \mathrm{C}$ por $2 \mathrm{~min}$, seguido de 35 ciclos a $95^{\circ} \mathrm{C}$ por 30 $\mathrm{s}, 55^{\circ} \mathrm{C}$ por $1 \mathrm{~min}$ y $72^{\circ} \mathrm{C}$ por $40 \mathrm{~s}$, con una extensión final a $72{ }^{\circ} \mathrm{C}$ por $3 \mathrm{~min}$. Los productos de amplificación se analizaron en geles de agarosa al $2 \%$ teñidos con bromuro de etidio y visualizados bajo luz UV. En cada reacción se incluyeron controles negativos de extracción y amplificación, y como controles positivos se incluyó ARN de los cuatro serotipos del virus, proveniente del sobrenadante de células infectadas y que se procesaron simultáneamente y de la misma manera que los pools de mosquitos. Para confirmar la positividad de los pools, se seleccionaron aleatoriamente el $15 \%$ de las muestras positivas a la infección con dengue que se obtuvo en mosquitos machos, en especial las conformadas por un solo ejemplar, para ser secuenciadas en Macrogen (Seúl, Korea). Las secuencias directas e inversas de cada una de las muestras se editaron manualmente, usando el programa BioEdit v.7.2.5 (Hall 1999) y comparadas con la base de datos del GenBank ${ }^{\circledR}$ mediante el algoritmo BLAST (National Center for Biotechnology Information 1988; Benson et al. 2015).

Análisis de la información. Para el presente estudio se consideró como indicador de transmisión vertical la ocurrencia de machos de Ae. aegypti y Ae. albopictus naturalmente infectados con virus dengue (Rosen 1987). Se calculó la Tasa Mínima de Infección (MIR, por sus siglas en inglés), dividiendo el número de pools positivos por el número total de mosquitos recolectados, y multiplicando por 1.000 (Walter et al. 1980). Para el cálculo de MIR se asumió el supuesto tradicional que un pool positivo corresponde a un único mosquito infectado, pero de acuerdo con Gu et al. (2003), este supuesto podría no ser válido cuando las tasas de infección son altas y/o el tamaño de los pools es elevado. Para compensar tal situación, se conformaron pools de máximo diez mosquitos. La información que se presenta es de tipo descriptiva, y compara, de forma espacio/temporal, la transmisión vertical de virus dengue por Ae. aegypti y Ae. albopictus.

\section{Resultados}

Ejemplares recolectados e infectividad natural con virus dengue. Se recolectaron 6.708 mosquitos adultos, de los cuales el $96 \%$ fueron Ae. aegypti (3.117 machos y 3.320 hembras). La cantidad restante fue Ae. albopictus (117 machos y 154 hembras). Los mosquitos de ambas especies se recolectaron con mayor frecuencia en 2017. Para el caso particular de Ae. albopictus, fue notable la mayor cantidad recolectada en el año endémico (Tablas 1 y 2).

Con los mosquitos recolectados se conformaron 2.211 pools (2.079 para Ae. aegypti y 132 para Ae. albopictus). El análisis molecular de ellos indicó que el 13,3\% fue positivo para infección con virus dengue (267 para Ae. aegypti y 27 para Ae. albopictus). A pesar que en el 2017 se conformó un mayor número de pools, en 2016, año epidémico, fue mayor la cantidad de pools positivos para machos de Ae. aegypti. Se observó un resultado contrario para los pools positivos de Ae. albopictus y para los pools de hembras de Ae. aegypti, los cuales fueron más abundantes en 2017 (Tablas 1 y 2).

Tabla 1. Información entomológica de los mosquitos Aedes aegypti recolectados durante los años 2016 (epidémico para dengue) y 2017 (endémico), en Medellín, Colombia.

\begin{tabular}{|c|c|c|c|c|c|c|c|c|c|c|c|}
\hline \multirow{3}{*}{ Período } & \multicolumn{11}{|c|}{ Aedes aegypti } \\
\hline & \multicolumn{2}{|c|}{ Colectados } & \multicolumn{3}{|c|}{ Pools conformados } & \multicolumn{3}{|c|}{ Pools positivos } & \multicolumn{3}{|c|}{ MIR } \\
\hline & Machos & hembras & $\begin{array}{c}\text { Machos (\# de } \\
\text { mosquitos) }\end{array}$ & $\begin{array}{c}\text { Hembras (\# de } \\
\text { mosquitos) }\end{array}$ & $\begin{array}{c}\text { Mixtos (\# de } \\
\text { mosquitos) }\end{array}$ & Machos & Hembras & Mixtos & Machos & Hembras & Mixtos \\
\hline 2016.I & 234 & 299 & $28(42)$ & $54(95)$ & 87 (396) & 10 & 26 & 28 & 238,1 & 273,7 & 70,7 \\
\hline 2016.II & 458 & 506 & $44(86)$ & $42(78)$ & $145(800)$ & 9 & 8 & 50 & 104,6 & 102,6 & 62,5 \\
\hline 2016.III & 286 & 292 & $43(70)$ & $54(99)$ & $91(409)$ & 4 & 4 & 11 & 57,1 & 40,4 & 26,9 \\
\hline 2016.IV & 422 & 378 & 69 (186) & $70(163)$ & $87(451)$ & 4 & 1 & 3 & 21,5 & 6,1 & 6,7 \\
\hline Total 2016 & 1.400 & 1.475 & $184(384)$ & $220(435)$ & $410(2.056)$ & 27 & 39 & 92 & 70,3 & 89,7 & 44,7 \\
\hline 2017.I & 261 & 289 & $52(103)$ & $65(108)$ & 75 (339) & 3 & 9 & 3 & 29,1 & 83,3 & 8,8 \\
\hline 2017.II & 411 & 411 & $113(150)$ & $122(169)$ & $126(503)$ & 11 & 14 & 8 & 73,3 & 82,8 & 15,9 \\
\hline 2017.III & 342 & 422 & $57(121)$ & 120 (199) & $110(444)$ & 2 & 11 & 8 & 16,5 & 55,3 & 18,0 \\
\hline 2017.IV & 703 & 723 & 74 (174) & $142(263)$ & 209 (989) & 2 & 18 & 20 & 11,5 & 68,4 & 20,2 \\
\hline Total 2017 & 1.717 & 1.845 & $296(548)$ & 449 (739) & $520(2.275)$ & 18 & 52 & 39 & 32,8 & 70,4 & 17,1 \\
\hline
\end{tabular}


Tabla 2. Información entomológica de los mosquitos Aedes albopictus recolectados durante los años 2016 (epidémico para dengue) y 2017 (endémico), en Medellín, Colombia.

\begin{tabular}{|c|c|c|c|c|c|c|c|c|c|c|c|}
\hline \multirow{3}{*}{ Período } & \multicolumn{11}{|c|}{ Aedes albopictus } \\
\hline & \multicolumn{2}{|c|}{ Colectados } & \multicolumn{3}{|c|}{ Pools conformados } & \multicolumn{3}{|c|}{ Pools positivos } & \multicolumn{3}{|c|}{ MIR } \\
\hline & Machos & hembras & $\begin{array}{c}\text { Machos (\# de } \\
\text { mosquitos) }\end{array}$ & $\begin{array}{l}\text { hembras (\# de } \\
\text { mosquitos) }\end{array}$ & $\begin{array}{c}\text { Mixtos (\# de } \\
\text { mosquitos) }\end{array}$ & Machos & Hembras & Mixtos & Machos & Hembras & Mixtos \\
\hline 2016.I & 0 & 2 & $0(0)$ & $2(2)$ & $0(0)$ & 0 & 1 & 0 & 0,0 & 500,0 & 0,0 \\
\hline 2016.II & 3 & 5 & $1(1)$ & $3(3)$ & $1(4)$ & 0 & 0 & 0 & 0,0 & 0,0 & 0,0 \\
\hline 2016.III & 3 & 6 & $2(4)$ & $0(0)$ & $1(5)$ & 0 & 0 & 1 & 0,0 & 0,0 & 200,0 \\
\hline 2016.IV & 0 & 3 & $0(0)$ & $3(3)$ & $0(0)$ & 0 & 2 & 0 & 0,0 & 666,7 & 0,0 \\
\hline Total 2016 & 6 & 16 & $3(5)$ & $8(8)$ & $2(9)$ & $\mathbf{0}$ & 3 & 1 & $\mathbf{0 , 0}$ & 375,0 & 111,1 \\
\hline 2017.I & 14 & 16 & $4(14)$ & $13(16)$ & $0(0)$ & 3 & 6 & 0 & 214,3 & 375,0 & 0,0 \\
\hline 2017.II & 17 & 22 & $5(17)$ & $30(22)$ & $0(0)$ & 2 & 9 & 0 & 117,6 & 409,1 & 0,0 \\
\hline 2017.III & 28 & 38 & $5(27)$ & $22(37)$ & $1(2)$ & 0 & 2 & 0 & 0,0 & 54,1 & 0,0 \\
\hline 2017.IV & 52 & 62 & $6(12)$ & $22(31)$ & $11(71)$ & 0 & 0 & 1 & 0,0 & 0,0 & 14,1 \\
\hline Total 2017 & 111 & 138 & $20(70)$ & 87 (106) & $12(73)$ & 5 & 17 & 1 & 71,4 & 160,4 & 13,7 \\
\hline
\end{tabular}

De acuerdo con el cálculo de MIR, los mayores valores para Ae. aegypti se observaron en el 2016 (Tabla 1), mientras que para el caso de Ae. albopictus, debido a la ausencia de pools positivos en varias ocasiones, no fue posible calcular los valores de MIR en todos los períodos evaluados (Tabla 2). Sin embargo, al comparar los valores de MIR para ambas especies, se observó que las tasas de infección fueron muy superiores en Ae. albopictus (Tablas 1 y 2).

Considerando solo los pools positivos se observó para Ae. aegypti que cerca del $17 \%$ de los pools en el 2016 correspondió exclusivamente a mosquitos machos, mientras que para el 2017, este porcentaje fue cercano al $14 \%$. Dichos porcentajes fueron lógicamente inferiores a los detectados en los pools de mosquitos hembra, los cuales correspondieron a $24,1 \%$ y $39,4 \%$, para los años 2016 y 2017 , respectivamente.
Para el caso de los pools conformados por ambos sexos, también se observó que el porcentaje de pools positivos a la infección con virus dengue fue superior al detectado en los pools de mosquitos machos, tanto para el 2016 como para el 2017 (Fig. 1).

Con relación a Ae. albopictus, se registró que los porcentajes de infección con virus dengue en los tres tipos de pools (machos, hembras, mezcla de ambos sexos), fueron inferiores a los detectados en Ae. aegypti, tanto en el 2016 como en el 2017. Al comparar por año los porcentajes de infección en $A e$. albopictus, se observó que los mayores valores se registraron en el 2017, particularmente para los pools de hembras y de machos. Es importante anotar que en el 2016 no se registró ningún pool de mosquitos machos de Ae. albopictus positivos para infección con virus dengue (Fig. 1).
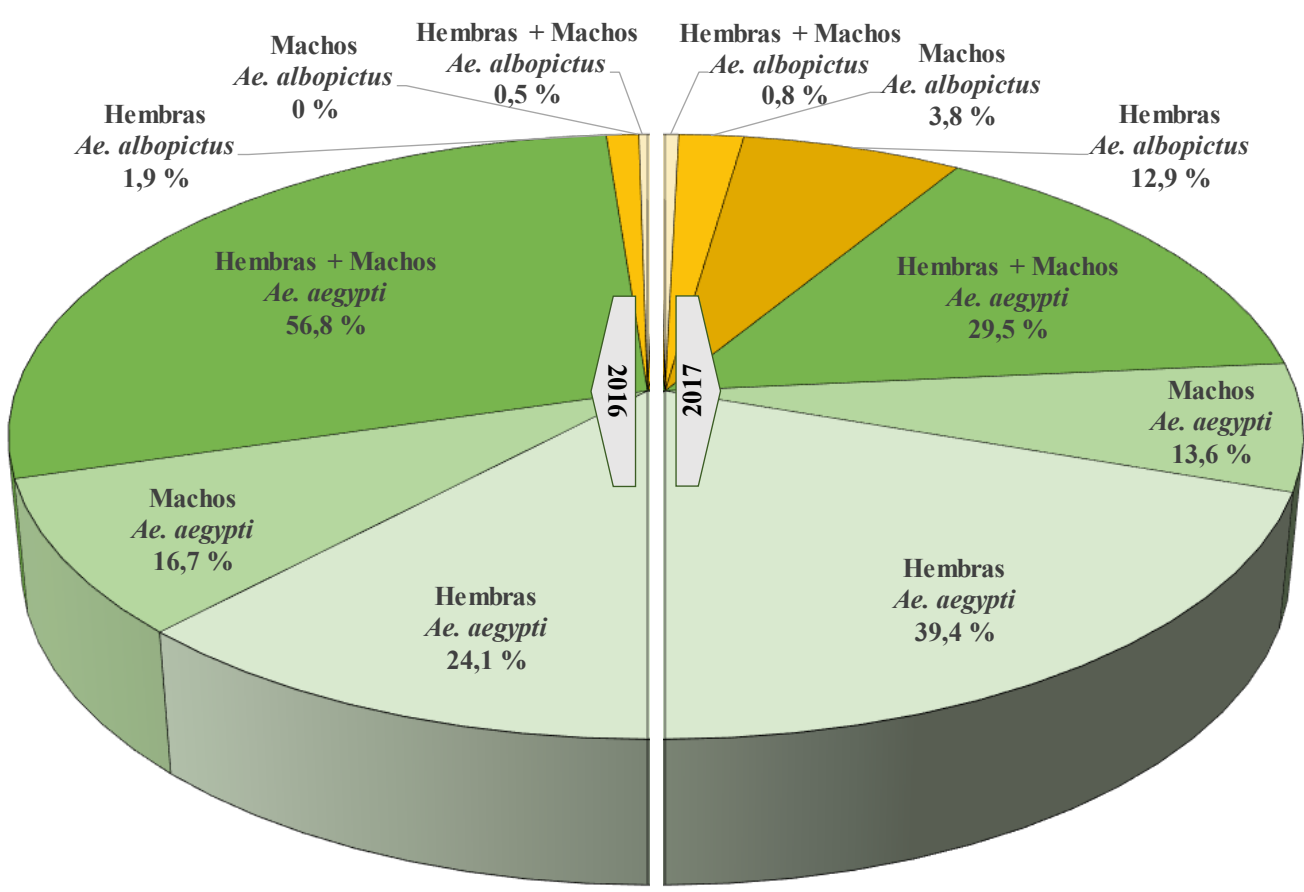

Figura 1. Distribución porcentual de los pools positivos para infección con virus dengue en mosquitos Aedes aegypti y Aedes albopictus recolectados durante los muestreos entomológicos realizados en los años 2016 (epidémico para dengue) y 2017 (endémico) en la ciudad de Medellín, Colombia. 
Transmisión vertical de virus dengue en Aedes spp. De los 294 pools positivos a la infección con virus dengue, el análisis molecular permitió detectar transmisión vertical en 50 de ellos. De estos, 45 pools correspondieron a Ae. aegypti y los demás a Ae. albopictus. Para el año epidémico se registró mayor cantidad de pools positivos para virus dengue en mosquitos machos Ae. aegypti, diferente a lo observado para Ae. albopictus.

Tanto en el 2016 como en el 2017, se detectó transmisión vertical de los cuatro serotipos de virus dengue en Ae. aegypti, correspondiendo los mayores valores a DENV-1. Mientras que para Ae. albopictus, solo se detectaron pools de machos infectados con el serotipo DENV-4. Además, en siete de los 50 pools identificados para la transmisión vertical, se observó infección simultánea con más de un serotipo del virus (Fig. 2). Particularmente, seis de estos pools estuvieron conformados por un solo mosquito, indicando infección heteroserotípica. En tal tipo de infección se determinó la combinación de solo dos serotipos, siendo los arreglos DENV-1/DENV-2, DENV1/DENV-3, DENV-1/DENV-4, DENV-2/DENV-3 y DENV2/DENV-4 los detectados en los mosquitos machos (Tabla 3). De manera coincidente, se observó que la gran mayoría de la infección heteroserotípica se registró en el año epidémico, período en el cual también se detectaron los mayores porcentajes de pools positivos para virus dengue.

De acuerdo con el análisis de las secuencias, los resultados del BLAST mostraron que los pools 315 y 380, presentaron alta identidad con la cepa DENV-3-254 (GenBank acceso No. KU509278.1) correspondiente al serotipo 3, con valores E de $2 \times 10^{-100}$ y $3 \times 10^{-89}$, respectivamente.

En cuanto a la distribución geográfica de los pools de mosquitos Ae. aegypti machos naturalmente infectados con virus dengue, se detectó transmisión vertical en diferentes sectores de la ciudad, correspondiendo los mayores valores en el 2016 a las zonas noroccidental y suroccidental, mientras que en el año 2017 se observó mayor cantidad de pools positivos en el nororiente de la ciudad. Además, se observó que los serotipos se distribuyeron de forma heterogénea por toda la ciudad, sin presentar un patrón definido, y fluctuando de un año para otro (Fig. 3). Para el caso de Ae. albopictus, los cinco pools positivos para virus dengue en mosquitos machos se distribuyeron en las zonas nororiental (2), noroccidental (2) y centro oriental (1).

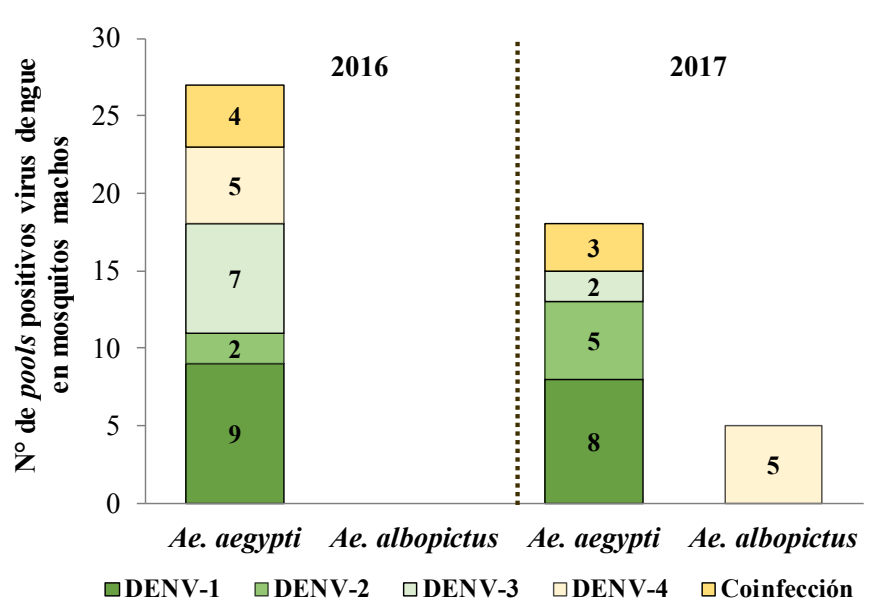

Figura 2. Distribución de la cantidad de serotipos de virus dengue en mosquitos machos Aedes aegypti y Aedes albopictus infectados naturalmente, y recolectados durante los años 2016 (epidémico para dengue) y 2017 (endémico) en la ciudad de Medellín, Colombia.

\section{Discusión}

En este estudio se evidenció la ocurrencia de transmisión vertical de virus dengue por mosquitos Ae aegypti y Ae. albopictus. Este resultado correspondió a la detección de un elevado porcentaje de pools de mosquitos machos naturalmente infectados con el virus. La infección natural en mosquitos machos, como indicador de transmisión vertical de dengue, ha sido un hallazgo relativamente común en estudios realizados en diferentes partes del mundo, entre los que se destacan el de Kow et al. (2001) en Singapur, Arunachalam et al. (2008) en Tamil Nadu, India; Thavara et al. (2006) en Tailandia y Espinosa et al. (2014) en Misiones, Argentina. En estos estudios, el porcentaje de machos naturalmente infectados con virus dengue varió notablemente, fluctuando entre 1,33 y $15,1 \%$, este último valor fue muy similar al encontrado en el presente estudio. Es posible que la diferencia en los porcentajes de mosquitos machos naturalmente infectados se deba al momento en que se recolectaron los ejemplares. En el presente estudio, los ejemplares se colectaron durante un año epidémico y otro endémico, y fue justamente en el primero en donde se detectó mayor transmisión vertical de virus dengue por Aedes spp. De manera concordante, en dicho año se registró la más grave epidemia de dengue de la que se tenga reporte en Medellín (Instituto Nacional de Salud 2016).

Pero no todos los estudios en transmisión vertical han dado resultados positivos. En Puerto Triunfo (Antioquia, Colombia) Romero-Vivas et al. (1998) evaluaron mediante la prueba de inmunofluorescencia indirecta (IFA) la infectividad con virus dengue en 1.552 machos de Ae. aegypti, sin detectar infección viral. También Watts et al. (1985) analizaron más de seis mil ejemplares, entre larvas, pupas y adultos machos de Ae. aegypti y Ae. albopictus provenientes de Bangkok y Ban Yang (Tailandia). Los investigadores reportaron que los aislamientos virales fueron negativos en las diferentes muestras evaluadas, pero sí lograron detectar infección con DENV-2 en el $5 \%$ de los mosquitos hembras colectadas en la misma zona de estudio. También en Tailandia, Hutamai et al. (2007), empleando la técnica de análisis de amplificación

Tabla 3. Infección heteroserotípica en mosquitos machos y hembras de Aedes aegypti y Aedes albopictus recolectados durante los años 2016 (epidémico para dengue) y 2017 (endémico), en Medellín, Colombia.

\begin{tabular}{|c|c|c|c|c|c|}
\hline \multicolumn{2}{|c|}{ Período } & \multirow{2}{*}{$\begin{array}{c}\text { Especie } \\
\text { Ae. aegypti }\end{array}$} & \multirow{2}{*}{$\frac{\text { Machos }}{1}$} & \multirow{2}{*}{$\frac{\text { Hembras }}{0}$} & \multirow{2}{*}{$\frac{\text { Serotipos }}{1 \mathrm{y} 4}$} \\
\hline \multirow{11}{*}{2016} & I & & & & \\
\hline & I & Ae. aegypti & 0 & 1 & 1 y 4 \\
\hline & I & Ae. aegypti & 0 & 1 & 1 y 4 \\
\hline & I & Ae. aegypti & 0 & 1 & 1 y 4 \\
\hline & II & Ae. aegypti & 1 & 0 & 2 y 3 \\
\hline & II & Ae. aegypti & 1 & 0 & 2 y 3 \\
\hline & II & Ae. aegypti & 1 & 0 & 2 y 3 \\
\hline & II & Ae. aegypti & 0 & 1 & 2 y 3 \\
\hline & II & Ae. aegypti & 0 & 1 & 2 y 3 \\
\hline & III & Ae. aegypti & 0 & 1 & 1 y 3 \\
\hline & IV & Ae. albopictus & 0 & 1 & 1 y 3 \\
\hline \multirow{2}{*}{2017} & II & Ae. aegypti & 1 & 0 & 1 y 2 \\
\hline & II & Ae. aegypti & 1 & 0 & 1 у 2 \\
\hline
\end{tabular}

*En gris se presentan los pools de mosquitos machos Ae. aegypti conformados por un solo individuo, y que resultaron infectados simultáneamente con diferentes serotipos de virus dengue, en un año epidémico y otro endémico en Medellín, Colombia. 


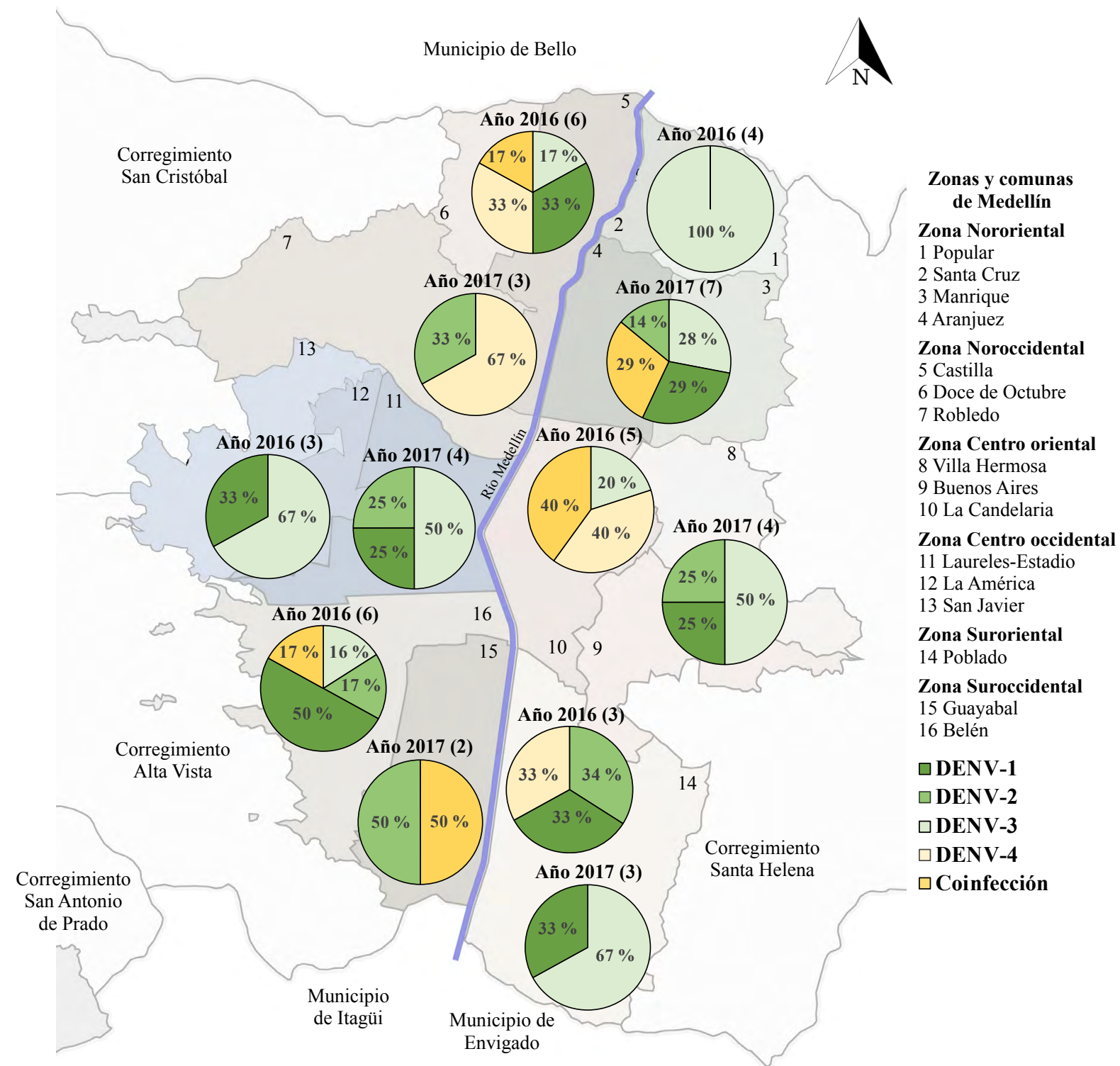

Figura 3. Distribución geográfica de los serotipos de virus dengue en mosquitos machos Aedes aegypti infectados naturalmente, recolectados durante los años 2016 (epidémico para dengue) y 2017 (endémico) en la ciudad de Medellín, Colombia. *Entre paréntesis se indica por cada año y zona de la ciudad, el número de pools positivos para infección con virus dengue en mosquitos machos Aedes aegypti. Mapa 'Comunas de Medellín' modificado de Wikipedia (2009).

basada en secuencias de ácidos nucleicos (NASBA por sus siglas en inglés), evaluaron más de diez mil mosquitos adultos, entre Ae. Aegypti y Ae. albopictus, provenientes de estados inmaduros recolectados en áreas epidémicas de dengue. Los resultados de este estudio mostraron que ninguna de las muestras fue positiva para la infección viral. Es posible que los resultados negativos en transmisión vertical estén relacionados con la sensibilidad de las técnicas con que se evaluó la infección en los mosquitos, lo cual ha sido demostrado por Thongrungkiat et al. (2011), entre otros, al detectar por RT-PCR transmisión vertical de virus dengue en mosquitos Aedes spp.

Otros estudios que también han confirmado transmisión vertical natural de virus dengue en Aedes spp., han empleado mosquitos adultos emergidos en condiciones de laboratorio, y procedentes de estados inmaduros (huevos, larvas y/o pupas) recolectados en localidades endémicas para la enfermedad. En Mato Grosso (Brasil), Cruz et al. (2015) colectaron huevos empleando ovitrampas, y al procesar por RT-PCR los mosquitos adultos obtenidos, observaron que el $10 \%$ de los pools positivos para virus dengue correspondieron a machos de Ae. aegypti. También Le Goff et al. (2011) en Santa Cruz de La Sierra (Bolivia), detectaron transmisión vertical de virus dengue en machos Ae. aegypti, en un porcentaje coincidente con el estudio anterior. Hallazgos similares han sido reportados en Rangoon (Birmania) (Khin y Than 1983) y Surabaya (Indonesia) (Mulyatno et al. 2012), entre otros.

Bajo condiciones experimentales también se ha detectado transmisión vertical de virus dengue en mosquitos machos. Uno de los trabajos pioneros en el tema fue el realizado por Rosen (1987), quien evidenció que machos Ae. albopictus, infectados experimentalmente con virus dengue, transmiten el virus tanto a la progenie $\mathrm{F} 1$ como al mosquito hembra durante la cópula. También demostró que las hembras infectadas no transmiten sexualmente la infección a los mosquitos machos. A pesar de que estos experimentos se realizaron con $A e$. 
albopictus, también se ha reportado ampliamente transmisión vertical de virus dengue en Ae. aegypti (Rosen 1987; Joshi et al. 2002; Vilela et al. 2010; Martins et al. 2012).

De acuerdo con los resultados de los anteriores estudios, y la revisión de Ferreira-De-Lima y Lima-Camara (2018), es posible indicar que la transmisión vertical de virus dengue en Ae. aegypti y Ae. albopictus es un mecanismo generalizado de infección viral en mosquitos en diferentes partes del mundo, $\mathrm{y}$ más frecuente de lo que realmente se ha considerado.

En cuanto al MIR, se ha indicado que en su cálculo podría subestimar la infección viral, ya que se asume que un pool positivo corresponde a un solo mosquito infectado, de ahí que muchos autores no consideren su uso (Gu et al. 2004; Bustamante y Lord 2010). Para subsanar esta situación, en el presente estudio se conformaron pools con un máximo de diez mosquitos, y de acuerdo con los resultados, se observó que MIR para los machos Ae. aegypti fue lógicamente menor que el detectado para las hembras. Particularmente para los machos, los mayores valores se registraron en el primer semestre del año, lo cual no coincide con los hallazgos de Arunachalam et al. (2008), quienes observaron en Tamil Nadu (India) que la tasa de infección natural con virus dengue en machos $A e$. aegypti fue mayor en junio y julio. Es importante anotar que la falta de concordancia entre ambos estudios podría deberse a que en Medellín, las colectas de mosquitos se realizaron durante un año epidémico, mientras que en India las colectas se realizaron en períodos de baja transmisión.

Al comparar MIR para ambas especies se observaron los mayores valores en Ae. albopictus. Este resultado concuerda con lo reportado en Brasil por Martins et al. (2012), y para el presente estudio podría explicarse por la alta proporción de Ae. albopictus infectados con virus dengue, en un bajo número de ejemplares recolectados. Es posible también que Ae. albopictus esté ganando relevancia epidemiológica en la transmisión de dengue en Medellín, lo cual podría verificarse no solo por los elevados valores de MIR registrados en el presente estudio, sino también por los procesos de urbanización y aumento paulatino en la distribución geográfica reportado para esta especie en la ciudad (Pérez-Pérez et al. 2018).

Se ha argumentado que la transmisión vertical de virus dengue por mosquitos Aedes es un importante mecanismo para el mantenimiento del virus en la naturaleza, convirtiéndolos no solo en vectores sino también en reservorios del virus (Le Goff et al. 2011). Además, la historia natural sugiere que este tipo de virus se adaptó inicialmente al mosquito hospedero para luego infectar a los primates, y entre ellos los humanos (Cecílio et al. 2009). Como respaldo a los anteriores enunciados, se ha observado que el virus puede transmitirse verticalmente de generación en generación, hasta la séptima descendencia (Shroyer 1990; Joshi et al. 2002; Rohani et al. 2007). Con base en lo anterior, y al gran número de estudios en diferentes partes del mundo que reportan la ocurrencia de transmisión vertical natural de virus dengue en Aedes, se podría considerar que el costo de este mecanismo de transmisión sería superior al calculado en el modelo matemático desarrollado por Adams y Boots (2010). Además, debería considerarse que la ocurrencia de mosquitos machos infectados verticalmente, sugiere también la presencia de hembras igualmente infectadas con el virus. Tales hembras no tendrían que pasar por el período de incubación extrínseco para transmitir el virus a los humanos, lo cual potenciaría la dinámica de transmisión de dengue, $\mathrm{y}$ podría ayudar a explicar los brotes epidémicos que se registran periódicamente en localidades endémicas.
En el presente estudio se observó infección heteroserotípica de dengue en mosquitos machos Ae. aegypti. Este hallazgo también ha sido encontrado en otras investigaciones, como en el caso de Thavara et al. (2006) en algunas provincias del sur de Tailandia, Angel et al. (2015) en Rajastán, India y Pessanha et al. (2011) en Belo Horizonte, Brasil.

Con base en lo anterior y de acuerdo con el conceso científico que indica que la infección con dos diferentes serotipos de virus dengue en humanos, conlleva a una forma grave de la enfermedad (Guzmán et al. 2002; Álvarez et al. 2006), sería importante tener en cuenta que la ocurrencia de infección simultánea con varios serotipos de dengue en un mismo mosquito podría jugar un papel significativo en la compleja dinámica de la transmisión de la enfermedad. Sin embargo, la importancia de la transmisión vertical en la epidemiologia de dengue es un tópico que ha generado amplia controversia científica (Grunnill y Boots 2016) debido a que aún no se ha precisado su papel en la incidencia de la enfermedad.

Particularmente, en el presente estudio se observó que los mayores valores de transmisión vertical de virus dengue en mosquitos Aedes se presentaron simultáneamente durante el año epidémico de la enfermedad. Relaciones similares también han sido evidenciadas en Malasia (Lee y Rohani 2005), Singapur (Lee et al. 2010) y Bolivia (Le Goff et al. 2011). Además, Thongrungkiat et al. (2011) registraron altas tasas de transmisión vertical antes del período de máxima transmisión de dengue en Bangkok (Tailandia), demostrando la importancia del monitoreo viral en mosquitos como un sistema de alerta temprana. En este sentido, la transmisión vertical podría comprender una mayor relevancia epidemiológica de la que actualmente se considera. Sin embargo, son necesarios estudios adicionales que permitan verificar la capacidad de replicación e infección del virus transmitido de esta forma, con el fin de precisar el papel de la transmisión vertical en las incidencias de dengue.

Es importante resaltar que la vigilancia virológica en mosquitos, de la cual la detección de transmisión vertical hace parte, es un proceso de gran utilidad para apoyar la toma de decisiones en la vigilancia, prevención y control de dengue. Particularmente, el cálculo de MIR podría ayudar a monitorear la circulación e intensidad espacio/temporal de la infectividad natural de virus dengue en mosquitos, tal como se ha propuesto en diferentes estudios (Edillo et al. 2015; Da-Costa et al. 2017).

\section{Conclusiones}

Los resultados del presente estudio contribuyen a mejorar el entendimiento de la compleja dinámica de transmisión de dengue y deben conllevar a considerar que durante los brotes de dengue, las estrategias de control no solo se enfoquen en la eliminación de mosquitos adultos, como tradicionalmente se propone, sino también, se orienten a intensificar la eliminación de criaderos debido al mecanismo de transmisión vertical del virus dengue presente en el vector, y que ha sido ampliamente reportado.

\section{Agradecimientos}

Los autores deseamos expresar nuestros agradecimientos a las personas que permitieron el ingreso a sus viviendas para realizar los muestreos entomológicos. A la Secretaría de Salud de Medellín por el apoyo logístico para la 
realización de los muestreos y por facilitar la información entomológica, virológica y epidemiológica. También nuestros agradecimientos al Grupo Entomología Médica, Facultad de Medicina, Universidad de Antioquia. Además, manifestamos que no existe ningún conflicto de intereses relacionados con los resultados presentados en este documento.

Este estudio fue realizado gracias a los convenios interadministrativos firmados entre la Secretaría de Salud de Medellín y la Universidad de Antioquia (Grupo Entomología Médica, Facultad de Medicina), y al apoyo financiero de COLCIENCIAS (contrato 634-2017, proyecto 111574455690).

\section{Literatura citada}

ADAMS, B.; BOOTS, M. 2010. How important is vertical transmission in mosquitoes for the persistence of dengue? Insights from a mathematical model. Epidemics 2 (1): 1-10. https://doi.org/10.1016/j.epidem.2010.01.001

ALCALDÍA DE MEDELLÍN. 2003. Datos generales de la ciudad. Disponible en: https://www.medellin.gov.co/irj/portal/medelli n?NavigationTarget=navurl://6488ef50a6787e $1 \mathrm{fdbc} 4 \mathrm{e} 42 \mathrm{e} 62 \mathrm{a} 4$ 6 a67 [Fecha revisión: 29 julio 2019].

ÁlVAREZ, M.; RODRIGUEZ-ROCHE, R.; BERNARDO, L.; VÁZQUEZ, S.; MORIER, L.; GONZALEZ, D.; CASTRO, O.; KOURI, G.; HALSTEAD, S. B.; GUZMAN, M. G. 2006. Dengue hemorrhagic fever caused by sequential dengue 1-3 virus infections over a long time interval: Havana epidemic, 20012002. The American Journal of Tropical Medicine and Hygiene 75 (6): 1113-1117. https://doi.org/10.4269/ajtmh.2006.75.1113

ANGEL, B.; ANGEL, A.; JOSHI, V. 2015. Multiple dengue virus types harbored by individual mosquitoes. Acta Tropica 150: 107110. https://doi.org/10.1016/j.actatropica.2015.07.007

ARUNACHALAM, N.; TEWARI, S. C; THENMOZHI, V.; RAJENDRAN, R.; PARAMASIVAN, R.; MANAVALAN, R.; AYANAR, K, TYAGI, B. K. 2008. Natural vertical transmission of dengue viruses by Aedes aegypti in Chennai, Tamil Nadu, India. Indian Journal of Medical Research 127 (4): 395-397.

BENSON, D. A.; CLARK, K.; KARSCH-MIZRACHI, I.; LIPMAN, D. J.; OSTELL, J.; SAYERS, E. W. 2015. GenBank. Nucleic Acids Research Jan; 43 (Database issue): D30-35. https://doi. org/10.1093/nar/gku1216

BHATT, S.; GETHING, P. W.; BRADY, O. J.; MESSINA, J. P.; FARLOW, A. W.; MOYES, C. L.; DRAKE, J. M.; BROWNSTEIN, J. S.; HOEN, A. G.; SANKOH, O.; MYERS.; M. F.; GEORGE, D. B.; JAENISCH, T.; WINT, G. R.; SIMMONS, C. P.; SCOTT, T. W.; FARRAR, J. J.; HAY, S. I. 2013. The global distribution and burden of dengue. Nature 496: 504-507. https://doi.org/10.1038/nature 12060

BUSTAMANTE, D. M.; LORD, C. C. 2010. Sources of error in the estimation of mosquito infection rates used to assess risk of arbovirus transmission. The American Journal of Tropical Medicine and Hygiene 82 (6): 1172-1184. https://doi. org/10.4269/ajtmh.2010.09-0323

CECÍlIO, A. B.; CAMPANELli, E. S.; SOUZA, K. P. R.; FIGUEIREDO, L. B.; RESENDE, M. C. 2009. Natural vertical transmission by Stegomyia albopicta as dengue vector in Brazil. Brazilian Journal of Biology 69 (1): 123-127. https://doi. org/10.1590/S1519-69842009000100015

CHOW, V. T.; CHAN, Y. C.; YONG, R.; LEE, K.; CHUNG, Y. K.; LAM-PHUA, S. G.; TAN, B. T. 1998. Monitoring of dengue viruses in field-caught Aedes aegypti and Aedes albopictus mosquitoes by a type-specific polymerase chain reaction and cycle sequencing. The American Journal of Tropical Medicine and Hygiene 58 (5): 578-586. https://doi.org/10.4269/ ajtmh.1998.58.578

CRUZ, L. C.; SERRA, O. P.; LEAL-SANTOS, F. A.; RIBEIRO, A. L.; SLHESSARENKO, R. D.; SANTOS, M. A. 2015. Natural transovarial transmission of dengue virus 4 in Aedes aegypti from Cuiabá, State of Mato Grosso, Brazil. Revista da Sociedade Brasileira de Medicina Tropical 48 (1): 18-25. https://doi. org/10.1590/0037-8682-0264-2014

DA COSTA, C. F.; DOS PASSOS, R. A.; LIMA, J. B. P.; APARECIDA-ROQUE， R.; DE-SOUZA-SAMPAIO, V.; BONIFÁCIO-CAMPOLINA, T.; COSTA-SECUNDINO, N. F.; PAOLUCCI-PIMENTA, P. F. 2017. Transovarial transmission of DENV in Aedes aegypti in the Amazon basin: a local model of xenomonitoring. Parasites \& Vectors 10: 249. https://doi. org/10.1186/s13071-017-2194-5

DUBOT-PÉRÈS, A.; VONGPHRACHANH, P.; DENNY, J.; PHETSOUVANH, R.; LINTHAVONG, S.; SENGKEOPRASEUTH, B.; KHASING, A.; XAYTHIDETH, V.; MOORE, C.; VONGSOUVATH, M.; CASTONGUAYVANIER, J.; SIBOUNHEUANG, B.; TAOJAIKONG, T.; CHANTHONGTHIP, A.; DE LAMBALLERIE, X.; NEWTON, P. N. 2013. An epidemic of Dengue-1 in a remote village in rural Laos. Plos Neglected Tropical Diseases 7 (8): 1-11 e2360. https://doi.org/10.1371/journal.pntd.0002360

EDILLO, F. E.; SARCOS, J. R.; SAYSON, S. L. 2015. Natural vertical transmission of dengue viruses in Aedes aegypti in selected sites in Cebu City, Philippines. Journal of Vector Ecology 40 (2): 282-291. https://doi.org/10.1111/jvec.12166

ESPINOSA, M.; GIAMPERETTI, S.; ABRIL, M.; SEIJO, A. 2014. Vertical transmission of dengue virus in Aedes aegypti collected in Puerto Iguazú, Misiones, Argentina. Revista do Instituto de Medicina Tropical de São Paulo 56 (2): 165-167. https://doi. org/10.1590/S0036-46652014000200013

FERREIRA-DE-LIMA, V. H.; LIMA-CAMARA, T. N. 2018. Natural vertical transmission of dengue virus in Aedes aegypti and Aedes albopictus: A systematic review. Parasites \& Vectors 11: 77. https://doi.org/10.1186/s13071-018-2643-9

GJENERO-MARGAN, I.; ALERAJ, B.; KRAJCAR, D.; LESNIKAR, V.; KLOBUČAR, A.; PEM-NOVOSEL, I.; KUREČIĆFILIPOVIĆ, S.; KOMPARAK, S.; MARTIĆ, R.; DURIČIĆ, S.; BETICA-RADIĆ, L.; OKMADŽIĆ, J.; VILIBIĆ-ČAVLEK, T.; BABIĆ-ERCEG, A.; TURKOVIĆ, B.; AVSIĆ-ŽUPANC, T.; RADIĆ, I.; LJUBIĆ, M.; SARAC, K.; BENIĆ, N.; MLINARIĆGALINOVIĆ, G. 2011. Autochthonous dengue fever in Croatia, August- September 2011. Eurosurveillance 16 (9): 1-4.

GRATZ, N. G. 2004. Critical review of the vector status of Aedes albopictus. Medical and Veterinary Entomology 18 (3): 215-227. https://doi.org/10.1111/j.0269-283X.2004.00513.X

GRUNNILL, M.; BOOTS, M. 2016. How important is vertical transmission of dengue viruses by mosquitoes (Diptera: Culicidae)?. Journal of Medical Entomology 53 (1): 1-19. https://doi.org/10.1093/jme/tjv168

GU, W.; LAMPMAN, R.; NOVAK, R. J. 2003. Problems in estimating mosquito infection rates using minimum infection rate. Journal of Medical Entomology 40 (5): 595-596. https:// doi.org/10.1603/0022-2585-40.5.595

GU, W.; LAMPMAN, R.; NOVAK, R. J. 2004. Assessment of arbovirus vector infection rates using variable size pooling. Medical and Veterinary Entomology 18 (2): 200-204. https://doi. org/10.1111/j.0269-283X.2004.00482.x

GUBLER, D. J. 1989. Surveillance for dengue and dengue hemorrhagic fever. Bulletin of the Pan American Health Organization. 23 (4): 397-404.

GUZMÁN, M. G.; KOURÍ, G.; VALDÉS, L.; BRAVO, J.; VAZQUEZ, S.; HALSTEAD, S. B. 2002. Enhanced severity of secondary dengue-2 infections: death rates in 1981 and 1997 Cuban outbreaks. Revista Panamericana de Salud Pública 11 (4): 223-227. https://doi.org/10.1590/S1020-49892002000400003

HALL, T. A. 1999. BioEdit: a user-friendly biological sequence alignment editor and analysis program for Window 95/98/NT. Nucleic Acids Symposium Series 41: 95-98.

HUTAMAI, S.; SUWONKERD, W.; SUWANNCHOTE, N.; SOMBOON, P.; PRAPANTHADARA, L. A. 2007. A survey 
of dengue viral infection in Aedes aegypti and Aedes albopictus from re-epidemic areas in the north of Thailand using nucleic acid sequence based amplification assay. The Southeast Asian Journal of Tropical Medicine and Public Health 38 (3): 448-454.

INSTITUTO NACIONAL DE SALUD (INS). 2016. Boletín epidemiológico semanal. Semana epidemiológica 23 y 52. Disponible en: https://www.ins.gov.co/buscador-eventos/ Paginas/Vista-Boletin-Epidemilogico.aspx [Fecha revisión: 10 marzo 2017].

JOSHI, V.; MOURYA, D. T.; SHARMA, R. C. 2002. Persistence of dengue-3 virus through transovarial transmission passage in successive generations of Aedes aegypti mosquitoes. The American Journal of Tropical Medicine and Hygiene 67 (2): 158-161. https://doi.org/10.4269/ajtmh.2002.67.158

KHIN, M. M.; THAN, K. A. 1983. Transovarial transmission of dengue 2 virus by Aedes aegypti in nature. The American Journal of Tropical Medicine and Hygiene 32 (3): 590-594. https://doi. org/10.4269/ajtmh.1983.32.590

KOW, C. Y.; KOON, L L.; YIN, P. F. 2001. Detection of dengue viruses in field caught male Aedes aegypti and Aedes albopictus (Diptera: Culicidae) in Singapore by type-specific PCR. Journal of Medical Entomology 38 (4): 475-479. https://doi. org/10.1603/0022-2585-38.4.475

LEE, H.; ROHANI, A. 2005. Transovarial transmission of dengue virus in Aedes aegypti and Aedes albopictus in relation to dengue outbreak in an urban area in Malaysia. Dengue Bulletin 29: 106111.

LEE, K. S.; LAI, Y. L.; LO, S.; BARKHAM, T.; AW, P.; OOI, P. L.; TAI, J. C.; HIBBERD, M.; JOHANSSON, P.; KHOO, S. P.; NG, L. C. 2010. Dengue virus surveillance for early warning, Singapore. Emerging Infectious Diseases 16 (5): 847-849. https://doi.org/10.3201/eid1605.091006

LE GOFF, G.; REVOLLO, J.; GUERRA, M.; CRUZ, M.; BARJA SIMON, Z.; ROCA, Y.; VARGAS FLORÈS, J.; HERVÉ, J. P. 2011. Natural vertical transmission of dengue viruses by Aedes aegypti in Bolivia. Parasite (Paris, France) 18 (3): 277-280. https://doi.org/10.1051/parasite/2011183277

LEQUIME, S.; PAUL, R. E.; LAMBRECHTS, L. 2016. Determinants of arbovirus vertical transmission in mosquitoes. Plos Pathogens 12 (5): 1-14. https://doi.org/10.1371/journal.ppat.1005548

MARTINS, V. E. P.; ALENCAR, C. H.; KAMIMURA, M. T.; DECARVALHO-ARAÚJO, F. M.; DE-SIMONE, S. G.; FIREMANDUTRA, R.; FLORINDO-GUEDES, M. I. 2012. Occurrence of natural vertical transmission of dengue- 2 and dengue-3 viruses in Aedes aegypti and Aedes albopictus in Fortaleza, Ceará, Brazil. PLos One 7 (7): e41386. https://doi.org/10.1371/journal. pone. 0041386

MEDLOCK, J. M.; HANSFORD, K. M.; VERSTEIRT, V.; CULL, B.; KAMPEN, H.; FONTENILLE, D; HENDRICKX, G.; ZELLER, H.; VAN BORTEL, W.; SCHAFFNER, F. 2015. An entomological review of invasive mosquitoes in Europe. Bulletin of Entomological Research 105 (6): 637-663. https:// doi.org/10.1017/S0007485315000103

MULYATNO, K. C.; YAMANAKA, A.; YOTOPRANOTO, S.; KONISHI, E. 2012. Vertical transmission of dengue virus in Aedes aegypti collected in Surabaya, Indonesia, during 20082011. Japanese Journal of Infectious Diseases 65 (3): 274-276. https://doi.org/10.7883/yoken.65.274

MUSTAFA, M. S.; RASOTGI, V.; JAIN, S.; GUPTA, V. 2015. Discovery of fifth serotype of dengue virus (DENV-5): A new public health dilemma in dengue control. Medical Journal Armed Forces India 71 (1): 67-70. https://doi.org/10.1016/j. mjafi.2014.09.011

NATIONAL CENTER FOR BIOTECHNOLOGY INFORMATION (NCBI). 1988. Basic Local Alignment Search Tool (BLAST). National Library of Medicine (NLM), US National Institutes of Health (NIH) in Bethesda, MD, USA. Disponible en: https:// blast.ncbi.nlm.nih.gov/Blast.cgi [Fecha revisión: 25 febrero 2018].
PADILLA, J.; ROJAS, D., P.; SÁENZ-GÓMEZ, R. 2012. Dengue en Colombia: epidemiología de la reemergencia a la hiperendemia. Guías de impresión Ltda. Bogotá, Colombia. 250 p.

PÉREZ-PÉREZ, J.; SANABRIA, W. H.; RESTREPO, C.; ROJO, R.; HENAO, E.; TRIANA, O.; MEJIA, A. M.; CASTAÑO, S. M.; RÚA-URIBE, G. L. 2017. Vigilancia virológica de Aedes (Stegomyia) aegypti y Aedes (Stegomyia) albopictus como apoyo para la adopción de decisiones en el control del dengue en Medellín. Biomédica 37 (2): 155-166. https://doi.org/10.7705/ biomedica.v37i0.3467

PÉREZ-PÉREZ, J.; ORTIZ, R. C.; SANABRIA, W.; H.; RESTREPO, C.; ROJO, R.; HENAO, E.; RÚA-URIBE G. L. 2018. Situación actual del mosquito invasor Aedes (Stegomyia) albopictus (Diptera: Culicidae) en Medellín: seis años después de su primer reporte. pp. 201-215. En: INVAWET. Humedales tropicales, especies invasoras y salud. Red temática INVAWET 2015-2018 del Programa Iberoamericano de Ciencia y Tecnología para el Desarrollo, CYTED (Madrid - España). 456 p.

PESSANHA, J. E.; CAIAFFA, W. T.; CECILIO, A. B.; IANI, F. C; ARAUJO, S. C; NASCIMENTO, J. C.; KROON, E. G.; PROIETTI, F. A.; ARIAS, J. R. 2011. Cocirculation of two dengue virus serotypes in individual and pooled samples of Aedes aegypti and Aedes albopictus larvae. Revista da Sociedade Brasileira de Medicina Tropical 44 (1): 103-105. https://doi. org/10.1590/S0037-86822011000100023

ROHANI, A.; ZAMREE, I.; LEE, H. L.; MUSTAFAKAMAL, I.; NORJAIZA, M. J.; KAMILAN, D. 2007. Detection of transovarial dengue virus from field-caught Aedes aegypti and Ae. albopictus larvae using C6/36 cell culture and reverse transcriptase-polymerase chain reaction (RT-PCR) techniques. Dengue Bulletin 31: 47-57.

ROMERO-VIVAS, C. M.; LEAKE, C. J.; FALCONAR, A. K. 1998. Determination of dengue virus serotypes in individual Aedes aegypti mosquitoes in Colombia. Medical and Veterinary Entomology 12 (3): 284-288. https://doi.org/10.1046/j.13652915.1998.00117.x

ROSEN, L. 1987. Mechanism of vertical transmission of the dengue virus in mosquitoes. Comptes rendus de l'Academie des Sciences. Serie III, Sciences de la vie 304 (13): 347-350.

ROTH,A.; MERCIER, A.; LEPERS, C.; HOY, D.; DUITUTURAGA, S.; BENYON, E.; GUILLAUMOT, L.; SOUARÈS, Y. 2014. Concurrent outbreaks of dengue, chikungunya and Zika virus infections - an unprecedented epidemic wave of mosquito - borne viruses in the Pacific 2012-2014. Eurosurveillance 19 (41): 2-9. https://doi.org/10.2807/1560-7917.ES2014.19.41.20929

RUEDA, L. M. 2004. Pictorial keys for the identification of mosquitoes (Diptera: Culicidae) associated with dengue virus transmission. Zootaxa 589 (1): 1-60. https://doi.org/10.11646/zootaxa.589.1.1

RUIZ-LÓPEZ, F.; GONZÁLEZ-MAZO, A.; VÉLEZ-MIRA, A.; GÓMEZ, G.F.; ZULETA, L.; URIBE, S.; VÉLEZ-BERNAL, I. D. 2016. Presencia de Aedes (Stegomyia) aegypti (Linnaeus, 1762) y su infección natural con el virus dengue en alturas no registradas para Colombia. Biomédica 36 (2): 303-308. https:// doi.org/10.7705/biomedica.v36i2.3301

SISTEMA NACIONAL DE VIGILANCIA EN SALUD PÚBLICA (SIVIGILA) - INSTITUTO NACIONAL DE SALUD (INS). 2018a. 2018-2020 Portal web SIVIGILA. Disponible en: http:// portalsivigila.ins.gov.co/sivigila/index.php [Fecha revisión: 29 julio 2019].

SISTEMA NACIONAL DE VIGILANCIA EN SALUD PÚBLICA (SIVIGILA) - INSTITUTO NACIONAL DE SALUD (INS). 2018b. Enfermedades transmisibles. Disponible en: https:// www.ins.gov.co/Direcciones/Vigilancia/Paginas/Transmisibles. aspx [Fecha revisión: 29 julio 2019].

SHROYER, D. A. 1990. Vertical maintenance of dengue-1 virus in sequential generations of Aedes albopictus. Journal of the American Mosquito Control Association 6 (2): 312-314.

THAVARA, U.; SIRIYASATIEN, P.; TAWATSIN, A.; ASAVADACHANUKORN, P.; ANANTAPREECHA, S.; 
WONGWANICH, R.; MULLA, M. S. 2006. Double infections of heteroserotypes of dengue viruses in field populations of Aedes aegypti and Aedes albopictus (Diptera: Culcidae) and serological features of dengue viruses found in patients in southern Thailand. The Southeast Asian Journal of Tropical Medicine and Public Health 37 (3): 468-476.

THENMOZHI, V.; HIRIYAN, J. 2007. Natural vertical transmission of dengue virus in Aedes albopictus (Diptera: Culicidae) in Kerala, a southern Indian state. Japanese Journal of Infectious Diseases 60 (October): 245-249.

THONGRUNGKIAT, $\quad$ S.; $\quad$ MANEEKAN, P.; WASINPIYAMONGKOL, L.; PRUMMONGKOL, S. 2011. Prospective field study of transovarial dengue-virus transmission by two different forms of Aedes aegypti in an urban area of Bangkok, Thailand. Journal of Vector Ecology 36 (1): 147-152. https://doi.org/10.1111/j.1948-7134.2011.00151.x

VELANDIA, M. L.; CASTELLANOS, J. E. 2011. Virus del dengue : estructura y ciclo viral. Revista de la Asociación Colombiana de Infectología 15 (1): 33-43. https://doi.org/10.1016/S01239392(11)70074-1

VILELA, A. P. P.; FIGUEIREDO, L. B.; DOS-SANTOS, J. R.; EIRAS, A. E.; BONJARDIM, C. A.; FERREIRA, P. C. P.; KROON, E. G. 2010. Dengue virus 3 genotype I in Aedes aegypti mosquitoes and eggs, Brazil, 2005-2006. Emerging Infectious Diseases 16 (6): 989-992. https://doi.org/10.3201/ eid1606.091000

WALTER, S. D.; HILDRETH, S. W.; BEATY, B. J. 1980. Estimation of infection rates in populations of organisms using pools of variable size. American Journal of Epidemiology 112 (1): 124128. https://doi.org/10.1093/oxfordjournals.aje.a112961

WATTS, D. M.; HARRISON, B. A.; PANTUWATANA, S; KLEIN, T. A.; BURKE, D. S. 1985. Failure to detect natural transovarial transmission of dengue viruses by Aedes aegypti and Aedes albopictus (Diptera: Culicidae). Journal of Medical Entomology 22 (3): 261-265. https://doi.org/10.1093/jmedent/22.3.261

WIKIPEDIA. 2009. Mapa de las comunas de Medellín, Colombia. https://upload.wikimedia.org/wikipedia/commons/2/2a/ Comunas_de_Medellin.svg [Fecha revisión: 28 agosto 2018].
WORLD HEALTH ORGANIZATION (WHO). 2014. EB 136/24 Dengue: prevention and control. Disponible en: https://apps. who.int/gb/e/e_eb136.html [Fecha revisión: 11 marzo 2017].

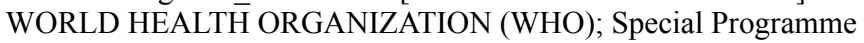
for Research and Training in Tropical Diseases (TDR). 2009. Dengue: Guidelines for diagnosis, treatment, prevention and control. World Health Organization. Geneva, Suiza. 147 p. https:// www.who.int/neglected_diseases/resources/9789241547871/en/

\section{Origen y financiación}

Este estudio fue un proyecto de investigación en donde se analizó la infección natural de mosquitos machos Aedes spp. como indicador de transmisión vertical, usando los datos obtenidos en el Programa de vigilancia, prevención y control de virus dengue, Zika y chikungunya a través del convenio SSM - UdeA (Grupo Entomología Médica) y el proyecto de COLCIENCIAS contrato 634-2017, proyecto 111574455690 .

\section{Contribución de los autores}

Guillermo L. Rúa-Uribe: Desarrollo de la idea, tabulación e interpretación de los datos, análisis de la información y escritura del manuscrito.

Tatiana M. Giraldo-Jaramillo: Tabulación de datos, análisis de información, escritura y revisión del manuscrito.

Omar Triana-Chávez: Análisis de información, escritura y revisión del manuscrito

Raúl Rojo: Análisis de información, escritura y revisión del manuscrito.

Enrique Henao: Análisis de información, escritura y revisión del manuscrito.

Juliana Pérez-Pérez: Tabulación de datos, análisis de información, escritura y revisión del manuscrito. 